\title{
Suplementação de vacas leiteiras com homeopatia: células somáticas do leite, cortisol e imunidade
}

\author{
[Supplementation of dairy cows with homeopathy: milk somatic cells, cortisol and immunity] \\ J.R.M. Silva ${ }^{1}$, L.L. Bitencourt ${ }^{2}$, B.M.L. Oliveira ${ }^{3}$, G.S. Dias Júnior ${ }^{4}$, F. Lopes ${ }^{5}$, \\ G.M.M. Caporale $^{6}$, K.C. Scheffer ${ }^{6}$, R.A.N. Pereira ${ }^{7}$, M.N. Pereira ${ }^{4 *}$ \\ ${ }^{1}$ Instituto Federal de Educação, Ciência e Tecnologia do Norte de Minas Gerais Campus Januária - Januária, MG \\ ${ }^{2}$ Instituto Federal de Educação - Ciência e Tecnologia do Espírito Santo - Campus Itapina - Colatina, MG \\ ${ }^{3}$ Universidade Presidente Antônio Carlos - Departamento de Veterinária - Juiz de Fora, MG \\ ${ }^{4}$ Universidade Federal de Lavras - Departamento de Zootecnia \\ Caixa Postal 3037 - 37200-000 - Lavras, MG \\ ${ }^{5}$ University of Wisconsin - Department of Dairy Science - Madison, EUA \\ ${ }^{6}$ Instituto Pasteur - Seção de Diagnóstico da Raiva - São Paulo, SP \\ ${ }^{7}$ Empresa de Pesquisa Agropecuária de Minas Gerais - Unidade Regional EPAMIG Sul de Minas - Lavras, MG
}

\section{RESUMO}

Avaliou-se o efeito da suplementação de uma combinação homeopática sobre a contagem de células somáticas do leite (CCS), o teor sanguíneo de cortisol e a resposta de anticorpos neutralizantes antivírus da raiva de vacas leiteiras. Trinta e duas vacas Holandesas em lactação foram blocadas em pares e aleatoriamente alocadas a um de dois tratamentos por 63 dias, posterior a um período de padronização de 14 dias. A CCS mensurada no final da padronização ajustou os valores semanais de CCS no modelo de análise estatística. Os tratamentos foram: 150 gramas de uma combinação homeopática (Hypothalamus, 10 ${ }^{-30}$; Colibacilinum, 10 ${ }^{-30}$; Streptococus Beta Hemolyticum, 10 $0^{-60}$; Streptococus Uberis, 10 ${ }^{-60}$; Phytolacca, 10 $0^{-60}$; Calcium Phosphoricum, 10 $0^{-30}$; Natrum Muriaticum, $10^{-60}$; Urtica Urens, $10^{-30}$; Silicea Terra, $10^{-400}$ ) em veículo mineral, ou 150 gramas do mesmo veículo mineral (controle). A homeopatia tendeu a aumentar a CCS de 124 para 222 x1.000 células mL ${ }^{-1}$ $(P=0,09)$ e a CCS linearizada $(P=0,08)$. Não foram detectados efeitos de tratamento sobre a concentração sérica de cortisol após estresse induzido por aspiração percutânea do saco ventral do rúmen $(P=0,59)$ ou sobre o título de anticorpos neutralizantes em resposta à vacinação antivírus da raiva $(P=0,40)$. A suplementação com homeopatia tendeu a aumentar a CCS de vacas com baixa CCS.

Palavras-chave: gado de leite, mastite, estresse, combinação homeopática

\begin{abstract}
The effect of supplementing a homeopathic combination on milk somatic cell count (SCC), blood cortisol content and the antibody response to rabies vaccination of dairy cows was evaluated. Thirty-two lactating Holstein cows were paired blocked and randomly assigned to one of two treatments for 63 days, following a 14-day standardization period. The SCC measured at the end of standardization period adjusted weekly SCC values in the statistical analysis model. Treatments were: 150 grams of a homeopathic combination (Hypothalamus, $10^{-30}$; Colibacilinum, $10^{-30}$; Streptococcus Beta Hemolyticum, $10^{-60}$. Streptococcus Uberis, $10^{-}$ ${ }^{60}$; Phytolacca, 10 10 ; Calcium Phosphoricum, 10 ${ }^{-30}$; Natrum Muriaticum, 10 ${ }^{-60}$; Urtica Urens, 10 $0^{-30}$, Silicea Terra, $10^{-400}$ ) in mineral vehicle, or 150 grams of the same mineral vehicle (Control). Homeopathy tended to increase SCC from 124 to $222 \times 1,000$ cells $\mathrm{mL}^{-1}(P=0.09)$ and linear SCC $(P=0.08)$. There were no detectable treatment effects upon serum cortisol concentration following stress induced by percutaneous aspiration of the ventral rumen $(P=0.59)$ and upon serum antibody title in response to rabies vaccination $(P=0.40)$. The supplementation with homeopathy tented to increase the SCC of low SCC cows.
\end{abstract}

Keywords: dairy cattle, mastitis, stress, homeopathic combination

Recebido em 19 de fevereiro de 2010

Aceito em 6 de abril de 2011

*Autor para correspondência (corresponding author).

E-mail: mpereira@dzo.ufla.br 


\section{INTRODUÇÃO}

Os compostos ou combinações homeopáticas, esporádica e erroneamente chamados de complexo homeopático (Yasgur, 2005), são a associação de homeopatias em uma única preparação. A origem do termo, neste contexto, advém da ocorrência de doenças chamadas complexas, nas quais duas doenças dissimilares instalam-se no mesmo indivíduo (Hahnemann, 1810; Aforisma 40). Combinações homeopáticas foram capazes de melhorar a resposta imune de ovinos com restrição alimentar (Chabel, 2007), de induzir redução na contagem de células somáticas (CCS) de vacas leiteiras (Moncayo, 2000) e de induzir cura de mastite clínica em vacas (Varshney e Naresh, 2005) e búfalas (Varshney e Naresh, 2004). Morales et al. (2005) também observaram redução da CCS do leite quando uma mistura de nosódios foi administrada a vacas com mastite clínica por curto espaço de tempo.

Entretanto, uma combinação homeopática utilizada com o intuito de promover preventivamente a saúde e a fertilidade de vacas leiteiras não resultou em resposta positiva (Fidelak et al., 2007). Mitidiero (2002) também observou que o uso por 11 meses de uma combinação homeopática para mastite aumentou a CCS do leite.

Teoricamente é impossível prever o comportamento de dois ou mais medicamentos homeopáticos combinados em uma mesma fórmula, um poderia obstruir ou alterar a resposta ao outro medicamento. Hahnemann (1810; Aforisma 274) alertou sobre o perigo de combinações homeopáticas quando a escolha medicamentosa não era feita em conformidade estrita ao conjunto de sintomas que se pretendia curar. Nestes casos, além de não induzir cura, o medicamento poderia provocar outros sintomas no paciente, aqueles previamente observados em testes do medicamento em indivíduos sadios (Hahnemann, 1810; Aforismas 121 a 141).

No entanto, o próprio questionamento histórico quanto à efetividade dos medicamentos homeopáticos (Hahnemann, 1842; Aforisma 269; rodapé 1; Kleijnen et al., 1991; Linde et al., 1994) resulta em um conceito pressuposto de seguridade aos animais e aos consumidores de alimentos oriundos de animais homeopatizados.
Este fato suporta a comercialização de combinações homeopáticas na terapêutica homeopática sem receita médica ou no uso da homeopatia como aditivo alimentar para induzir ganho no desempenho zootécnico de animais de produção.

O objetivo deste experimento foi avaliar o efeito da suplementação de vacas leiteiras com uma combinação homeopática comercial sobre a CCS do leite, o teor sanguíneo de cortisol após indução de estresse e a imunidade avaliada pela resposta de anticorpos neutralizantes à vacinação antivírus da raiva.

\section{MATERIAL E MÉTODOS}

Trinta e duas vacas Holandesas receberam um de dois tratamentos em delineamento do tipo blocos ao acaso, ajustado para mensurações da mesma variável no final de um período de padronização de 14 dias, e com estrutura de medidas repetidas ao longo de 63 dias. Descrição detalhada das unidades experimentais, dos tratamentos, dos métodos e do manejo alimentar adotado foi previamente descrita por Silva et al. (2011).

A fase experimental de coleta de dados ocorreu do dia 11/01/2006 ao dia 28/03/2006. Nesse período, a média das temperaturas mínimas dentro da instalação, mensurada às seis, 13 e 20 horas, foi de $21,2 \pm 2,4^{\circ} \mathrm{C}$, e a média das máximas de $27,3 \pm 4,0^{\circ} \mathrm{C}$. A média das temperaturas às seis, 13 e 20 horas foi de $21,8 \pm 3,3^{\circ} \mathrm{C}, 24,7 \pm 4,8^{\circ} \mathrm{C}$ e $26,2 \pm 4,2^{\circ} \mathrm{C}$, respectivamente.

O leite de cada vaca foi amostrado de seis ordenhas no final do período de padronização e de quatro ordenhas consecutivas nos dias seis e sete de cada uma das nove semanas do período de comparação para determinação da CCS. A CCS foi transformada em uma escala linear de 0 a 9 (CCS linear), sendo o ponto médio de cada escore linear representado pelos seguintes valores de CCS (x 1000 células $\mathrm{mL}^{-1}$ ): 12,5 para CCS linear 0; 25 para CCS linear 1; 50 para CCS linear 2; 100 para CCS linear 3; 200 para CCS linear 4; 400 para CCS linear 5; 800 para CCS linear 6; 1.600 para CCS linear 7; 3.200 para CCS linear 8 e 6.400 para CCS linear 9. Nos dias 12,13 e 14 do período de padronização, uma amostra do leite de cada vaca foi obtida para cultivo bacteriológico (Tecsa Laboratórios, Belo Horizonte, MG). O animal foi computado como 
positivo para determinado microrganismo quando ocorreu um ou mais isolamentos positivos em qualquer dos dias.

Amostras de sangue foram obtidas por punção dos vasos coccígeos para avaliação da resposta imune por dosagem de anticorpos neutralizantes antivírus da raiva em resposta à vacinação realizada no dia 35 do período de comparação. $\mathrm{O}$ rebanho foi rotineiramente vacinado para raiva, com primeira dose ao redor dos 90 dias de idade e segunda dose 30 dias após a primeira, e todo o rebanho foi vacinado a cada 10 meses. O título de anticorpos neutralizantes foi mensurado imediatamente antes da vacinação e, então, a múltiplos de sete dias por até 28 dias. As amostras de soro foram centrifugadas a $1000 \mathrm{xg}$ por 15 minutos, e o soro congelado a $-20^{\circ} \mathrm{C}$. O título de anticorpos neutralizantes foi avaliado por meio do microteste de inibição de fluorescência simplificado (SFIMT) (Favoretto et al., 1993).

No dia 63, amostras de fluido ruminal foram coletadas por ruminocentese. Para este procedimento, foi utilizada uma agulha 100x20mm para obtenção de fluido ruminal por punção percutânea do saco ventral do rúmen. Durante a amostragem do fluido ruminal, momento em que o fator estresse estaria elevado, amostras de sangue foram coletadas para mensuração da concentração de cortisol no soro. Uma amostra foi obtida de cada animal imediatamente antes da ruminocentese, duas outras amostras aos 15 e 45 minutos após o procedimento, e uma quarta amostra 12 horas após a aspiração percutânea do saco ventral do rúmen. As amostras foram centrifugadas a $1000 x$ g por 15 minutos, e o soro congelado a $20^{\circ} \mathrm{C}$. A determinação de cortisol foi realizada por quimioluminescência em laboratório comercial (Tecsa Laboratórios, Belo Horizonte, MG).

A CCS e a CCS linear foram analisadas como medidas repetidas pelo procedimento Mixed do SAS com um modelo contendo o efeito contínuo de covariável (medida da CCS e CCS linear no final do período de padronização) e os efeitos fixos de bloco (1 a 10), tratamento (homeopatia ou controle), semana (1 a 9) e interação entre tratamento e semana. A estrutura de covariância foi definida pelo critério de informação de Akaike, dentre autorregressiva de primeira ordem, não estruturada e simetria composta. O quadrado médio para o efeito de vaca dentro de tratamento foi utilizado como medida de erro para testar o efeito de tratamento. As variáveis anticorpos neutralizantes anti-vírus da raiva e cortisol também utilizaram modelo de medidas repetidas no tempo, entretanto a covariável foi a mensuração da variável no dia ou no tempo zero, e o efeito de semana foi substituído por dia, após a vacinação - 7, 14, 21 ou 63 -, ou minutos, após indução de estresse - 14, 45 ou 720.

\section{RESULTADOS E DISCUSSÃO}

Dentre os nove constituintes da associação homeopática, existiam três nosódios de microrganismos mamários, Calcium Phosphoricum - com indicação para controle de leite salgado em humanos (Boerick, 2009) -, e Phytolacca - um medicamento para inflamações glandulares (Boerick, 2009) -, um pacote para tratamento de mastite clínica. Entretanto, a CCS indicava que mastite não era um problema sério nas vacas deste experimento (Tab. 1). A proporção de animais com CCS abaixo de 100 mil células $\mathrm{mL}^{-1}$ no final da padronização era de 69\%, e CCS abaixo de 200 mil células 88\%. Dentre os 32 animais, dois apresentaram cultivo positivo para Staphylococcus aureus, um para Streptococcus bovis e quatro para Escherichia coli (Tab. 2). A frequência de cultivos positivos no final da padronização foi similar entre tratamentos.

Houve tendência de aumento da CCS nos animais homeopatizados (Tab. 1). O tratamento homeopático de animais sadios pode ter induzido aumento na CCS, e a dosagem medicamentosa dada ao longo de todo o período experimental, de nove semanas, pode ter sido excessiva (Hahnemann, 1810; Aforismas 275 a 283). Aumento de CCS também foi observado quando vacas leiteiras foram tratadas por 11 meses (Mitidiero, 2002) ou 15 dias (Mangieri Júnior et al., 2007) com homeopatia para mastite. Morales et al. (2005) relataram que o tratamento por apenas cinco dias reduziu a CCS em vacas com mastite subclínica, semelhantemente ao observado por Varshney e Naresh (2004), quando da medicação de quartos mamários clinicamente mastíticos de búfalas e de vacas leiteiras (Varshney e Naresh, 2005), apenas ao longo da manutenção dos sintomas clínicos. 
Tabela 1. Contagem de células somáticas (CCS) e CCS linear em vacas leiteiras suplementadas (Homeopatia) ou não (controle) com homeopatia

\begin{tabular}{|c|c|c|c|c|c|c|}
\hline & Homeopatia & Controle & EPM $^{1}$ & $P$ Trat $^{1}$ & $P$ Sem $^{1}$ & PInt $^{1}$ \\
\hline \multicolumn{7}{|c|}{ x 1.000 células $\mathrm{mL}^{-1}$} \\
\hline $\mathrm{CCS} 1^{2}$ & $222(16)$ & $124(16)$ & 39,28 & 0,09 & 0,45 & 0,92 \\
\hline $\operatorname{CCS} 2^{2}$ & $108(11)$ & $87(14)$ & 13,51 & 0,29 & 0,72 & 0,58 \\
\hline \multicolumn{7}{|c|}{0 a 9} \\
\hline CCS 1 linear & $2,89(16)$ & $2,28(16)$ & 0,232 & 0,08 & 0,57 & 0,59 \\
\hline CCS 2 linear & $2,50(11)$ & $2,09(14)$ & 0,166 & 0,10 & $<0,01$ & 0,15 \\
\hline \multicolumn{7}{|l|}{ CCS 1 linear ${ }^{3}$} \\
\hline$<50$ & $2,11(9)$ & $1,27(6)$ & 0,525 & 0,35 & $<0,01$ & 0,49 \\
\hline$<100$ & $2,46(12)$ & $1,60(10)$ & 0,310 & 0,08 & $<0,01$ & 0,28 \\
\hline$<200$ & $2,71(14)$ & $1,97(14)$ & 0,255 & 0,06 & 0,03 & 0,14 \\
\hline$<400$ & $2,87(15)$ & $2,11(15)$ & 0,230 & 0,03 & 0,13 & 0,26 \\
\hline$<800$ & $2,80(16)$ & $2,22(15)$ & 0,239 & 0,10 & 0,44 & 0,70 \\
\hline
\end{tabular}

${ }^{1} \mathrm{EPM}=$ =rro padrão das médias. Valor de probabilidade para os efeitos de Trat=tratamento; Sem=semana e Int=interação Trat $v s$. Sem.

${ }^{2} \mathrm{CCS} 1=$ todas as vacas; $\operatorname{CCS} 2=$ sem as vacas com mastite clínica.

${ }^{3}$ CCS 1 linear de vacas com CCS abaixo de 50 mil células $\mathrm{mL}^{-1}$ no final da padronização $(<50)$ a abaixo de 800 mil $(<800)$. Em parênteses o número de animais por tratamento em cada análise

Tabela 2. Número de vacas nos tratamentos homeopatia e controle com cultivo positivo de microrganismos no leite em pelo menos um dentre três dias amostrados no final da padronização

\begin{tabular}{lccc}
\hline & Homeopatia & Controle & Total \\
\hline Staphylococcus aureus & $2(6)$ & $0(0)$ & $2(6)$ \\
Staphylococcus sp coag. neg. & $5(10)$ & $4(12)$ & $9(22)$ \\
Streptococcus bovis & $0(0)$ & $1(2)$ & $1(2)$ \\
Escherichia coli & $2(2)$ & $2(2)$ & $4(4)$ \\
Bacillus SP & $7(10)$ & $9(11)$ & $16(21)$ \\
Cultivos positivos & $16(28)$ & $16(27)$ & $32(55)$ \\
\hline
\end{tabular}

Em parênteses, o número de amostras com cada ocorrência (48 amostragens por tratamento).

Apesar de relatos de resposta positiva em saúde animal ao uso de homeopatia, por curto prazo, este achado não tem sido uma constante. Werner e Sundrum (2006), na Alemanha, observaram que as taxas de cura de mastite clínica foram 36,2\% com homeopatia, 23,9\% com antibioticoterapia e 16,3\% com placebo, valores não diferentes estatisticamente, ao utilizarem 147 quartos mamários oriundos de 136 vacas. A cura foi definida como ausência de sinais clínicos, resultado negativo na bacteriologia e CCS abaixo de 100 mil células $\mathrm{mL}^{-1}$. Nesse caso, a homeopatia foi utilizada por, no mínimo, cinco dias e, no máximo, quatro semanas. Klocke et al. (2007) avaliaram a homeopatia para tratamento de mastite subclínica em 150 vacas de 17 rebanhos orgânicos da Suíça e observaram que o tratamento, dado por cinco dias, não foi efetivo.

O aumento de CCS em resposta ao tratamento prolongado com homeopatias para mastite tem sido interpretado como agravação homeopática (Mitidiero, 2002; Mangieri Júnior et al., 2007), algo desejável no tratamento homeopático de doenças crônicas (Hahnemann, 1833, 1842; Aforisma 279). Entretanto, o aumento nos sintomas de uma doença crônica em resposta ao uso de homeopatia apenas poderia ocorrer no final do tratamento, quando a cura estaria praticamente completa e, portanto, também a necessidade de medicação do sistema vital (Hahnemann, 1842; Aforisma 161). No tratamento ideal, o medicamento deveria ser administrado na dose baixa o suficiente (Hahnemann, 1810; Aforisma 15) para induzir no máximo uma leve doença medicamentosa, uma agravação homeopática, até algumas horas imediatamente após a ingestão (Hahnemann, 1842; Aforismas 157 a 161), não por semanas, como observado neste experimento (Fig. 1 e 2). 


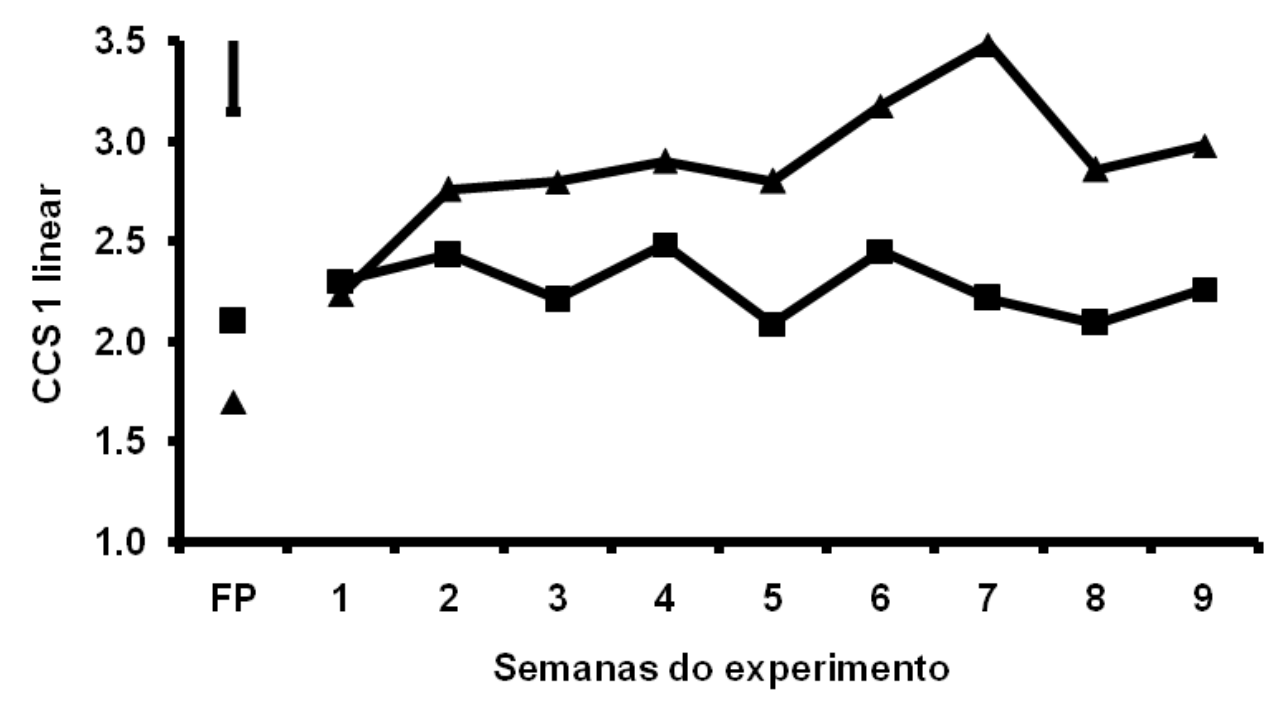

Figura 1. Contagem de células somáticas linear (CCS 1 linear). Valores ajustados para a medida da mesma variável no final da padronização (FP). ( $\Delta$ ) Homeopatia. ( $\mathbf{a})$ Controle $(P=0,08$ para o efeito de tratamento; $P=0,57$ para o efeito de semana; $P=0,59$ para interação tratamento $v s$. semana).

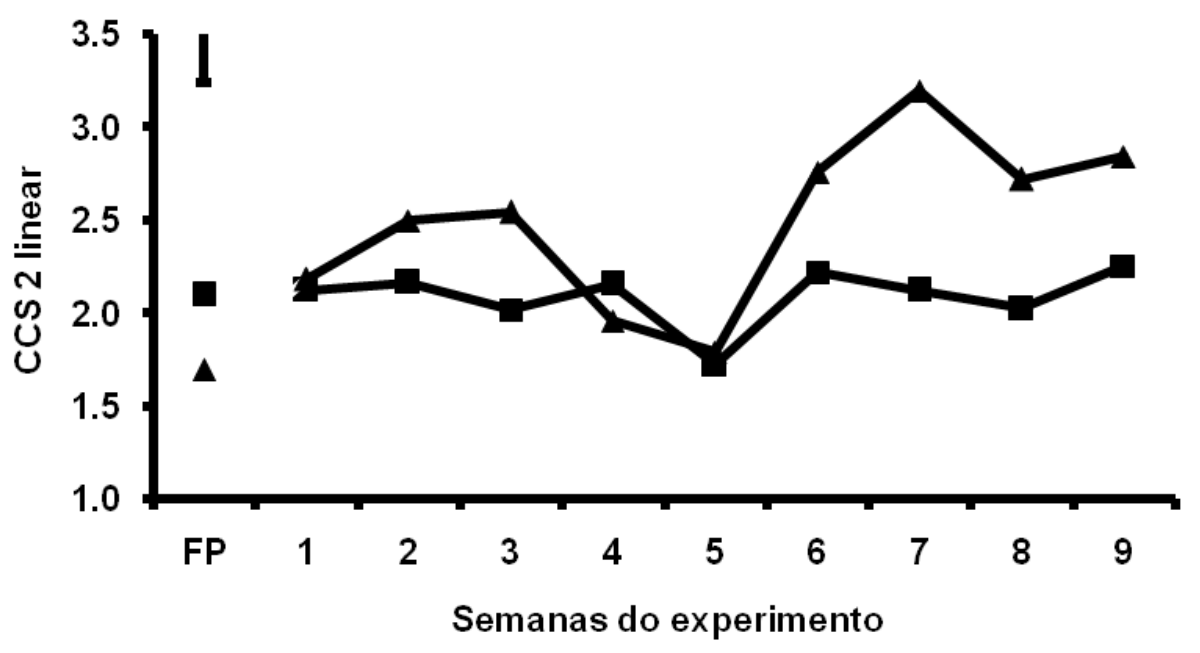

Figura 2. Contagem de células somáticas linear das vacas sem mastite clínica (CCS 2 linear). Valores ajustados para a medida da mesma variável no final da padronização (FP). ( $\mathbf{\Delta}$ ) Homeopatia. ( $\mathbf{a})$ Controle $(P=0,10$ para o efeito de tratamento; $P<0,01$ para o efeito de semana; $P=0,15$ para interação tratamento vs. semana).

O uso de tratamento prolongado em indivíduos sadios pode ter induzido uma doença medicinal (Hahnemann, 1810; Aforismas 157 a 160). Apesar de o número de unidades experimentais não ter sido grande o suficiente para dar suporte estatístico a esta observação, o número de mastites clínicas foi maior nas vacas homeopatizadas (Tab. 3). Os quadros clínicos observados foram típicos de mastite ambiental, coerentes à variação observada na CCS dos casos clínicos ao longo do período experimental. O uso da homeopatia para mastite, com as bases medicamentosas, dosagem e frequência adotadas neste trabalho, não se mostrou efetivo na manutenção da baixa CCS mensurada préexperimentalmente. 
Tabela 3. Contagem de células somáticas do leite (x 1000 células $\mathrm{mL}^{-1}$ ) das vacas com mastite clínica nos tratamentos homeopatia ou controle

\begin{tabular}{|c|c|c|c|c|c|c|c|c|c|c|c|}
\hline & & \multicolumn{10}{|c|}{ Semana experimental } \\
\hline Vaca & Sem $^{1}$ & $\mathrm{FP}^{1}$ & 1 & 2 & 3 & 4 & 5 & 6 & 7 & 8 & 9 \\
\hline & & & \multicolumn{9}{|c|}{ Controle } \\
\hline 1 & 4 & 1461 & 460 & 380 & 583 & 1661 & 1438 & 457 & 121 & 123 & 101 \\
\hline 2 & 1 & 191 & 192 & 648 & 151 & 288 & 276 & 397 & 289 & 180 & 159 \\
\hline & & & \multicolumn{9}{|c|}{ Homeopatia } \\
\hline 1 & 1 & 730 & 1731 & 786 & 400 & 279 & 225 & 178 & 69 & 69 & 102 \\
\hline 2 & 3 & 9 & 6 & 17 & 58 & 550 & 131 & 1030 & 136 & 47 & 25 \\
\hline 3 & 3 & 7 & 12 & 283 & 135 & 3530 & 1605 & 310 & 135 & 90 & 140 \\
\hline 4 & 4 & 216 & 271 & 200 & 365 & 537 & 2256 & 153 & 85 & 80 & 222 \\
\hline 5 & 7 & 36 & 12 & 35 & 26 & 28 & 91 & 44 & 3602 & 655 & 277 \\
\hline
\end{tabular}

${ }^{1} \mathrm{FP}=$ final da padronização; Sem=semana experimental de ocorrência da mastite clínica.

A agravação prolongada de sintomas medicamentosos não é coerente à cura gentil e totalmente salutar, um dos conceitos básicos da homeopatia (Hahnemann, 1842; Aforisma 157). Tratamentos homeopáticos preventivos, quando adotados em rebanhos, talvez exijam a adoção de protocolos medicamentosos provavelmente semelhantes aos adotados em testes de bases medicamentosas homeopáticas em indivíduos saudáveis (Hannemann, 1810. Aforismas 12 a 140). Estes podem ser benéficos, a se julgar pelo aumento relatado na robustez e na resistência a doenças de médicos homeopatas que continuamente avaliavam medicamentos neles mesmos para compreender sua ação e ganhar experiência com seu uso na cura de doentes (Hannemann, 1810. Aforisma 141). Fidelak et al. (2007) avaliaram o efeito de um protocolo homeopático fornecido no momento da secagem e no pós-parto como profilático de saúde e fertilidade de vacas leiteiras, sem encontrar efeito positivo.

Não foi detectado efeito da combinação homeopática sobre a concentração sérica de cortisol em resposta ao estresse da aspiração percutânea do rúmen (ruminocentese) (Tab. 4), apesar de a concentração sérica de cortisol ter sido numericamente menor nos animais homeopatizados (Fig. 3), o que é coerente com a resposta observada quando bases homeopáticas são administradas a animais sob estresse (Teixeira et al., 2003; Reis et al., 2006; Chabel, 2007). É interessante notar a alta resposta aguda em cortisol a esta técnica de amostragem do fluido ruminal (Fig. 4), evidenciando sua capacidade de induzir desconforto nos animais.

Não foi detectado efeito da homeopatia sobre o título de anticorpos neutralizantes anti-vírus da raiva em resposta à vacinação (Tab. 4). Curiosamente, a resposta dos animais homeopatizados foi numericamente pior, sugerindo uma resposta negativa quando homeopatias teoricamente indutoras de melhor imunidade foram administradas a um animal com sistema imune não debilitado. O rebanho era bem nutrido e sistematicamente vacinado contra raiva. Chabel (2007) observou, em ovinos, que uma mistura de Natrum Muriaticum, Calcium Carbonicum, Silicea Terra e Hypothalamus, semelhante à utilizada neste trabalho, induziu aumento no título de anticorpos neutralizantes antivírus da raiva em resposta à vacinação e reduziu o teor sanguíneo de cortisol apenas em animais nos quais o estresse foi induzido por restrição alimentar por 120 dias, sem efeito nos animais alimentados à vontade.

Tabela 4. Título de anticorpos neutralizantes antivírus da raiva e concentração de cortisol no soro de vacas leiteiras suplementadas (homeopatia) ou não (controle) com homeopatia

\begin{tabular}{|c|c|c|c|c|c|c|}
\hline & Homeopatia & Controle & EPM $^{1}$ & PTrat ${ }^{1}$ & PTemp ${ }^{1}$ & $P$ Int $^{1}$ \\
\hline \multicolumn{7}{|c|}{$\mathrm{UI} \mathrm{mL}^{-1}$} \\
\hline Anticorpos & 5,6 & 8,4 & 2,30 & 0,40 & 0,13 & 0,84 \\
\hline \multicolumn{7}{|c|}{$\eta \mathrm{g} \mathrm{mL}^{-1}$} \\
\hline Cortisol & 10,0 & 10,5 & 0,72 & 0,59 & $<0,01$ & 0,83 \\
\hline
\end{tabular}

${ }^{1}$ EPM=erro padrão das médias. Valor de probabilidade para os efeitos de Trat=tratamento; Temp=tempo (dia ou minuto) e Int=interação Trat $v s$. Temp. 


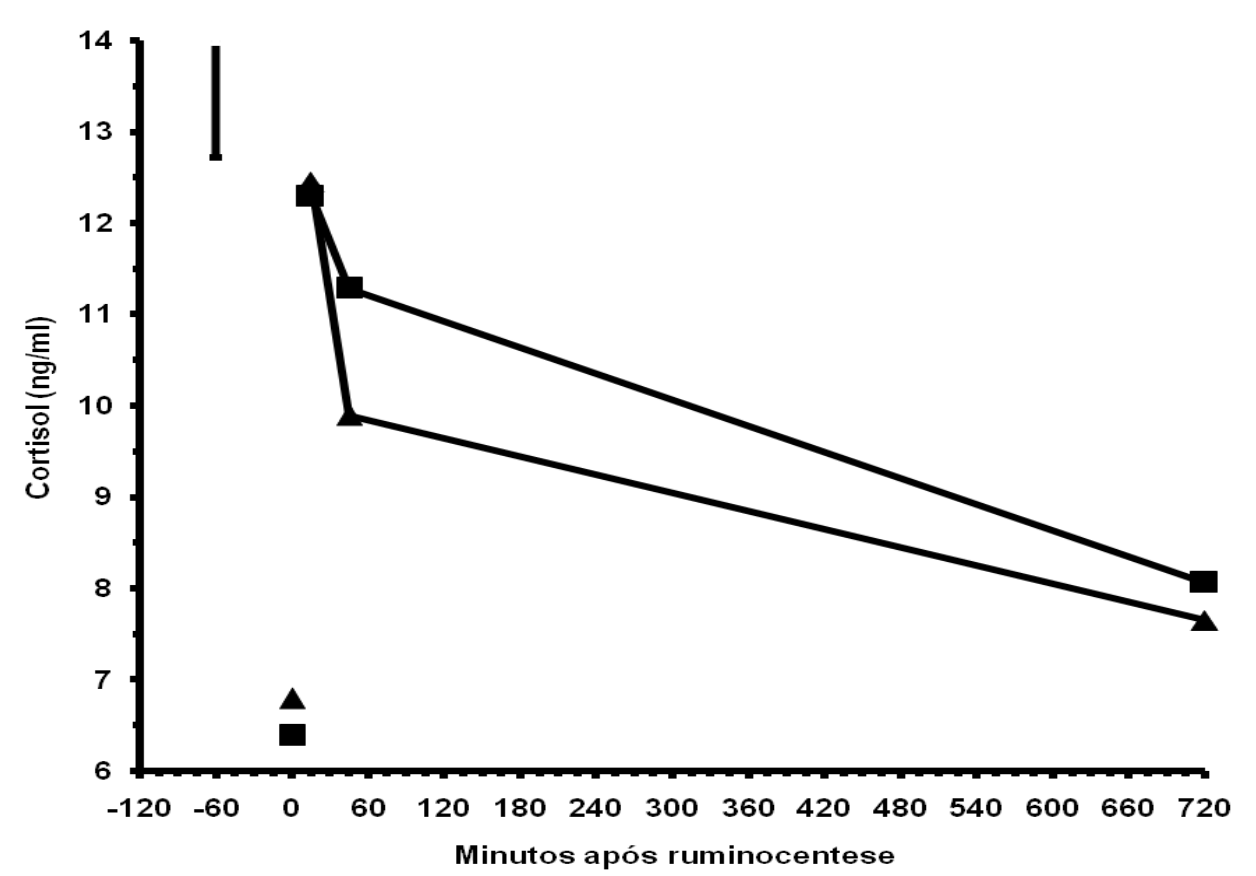

Figura 3. Teor de cortisol no soro após a aspiração percutânea do saco ventral do rúmen (ruminocentese). Valores ajustados para a medida da mesma variável imediatamente antes da ruminocentese (Tempo 0). (A) Homeopatia. (a) Controle.

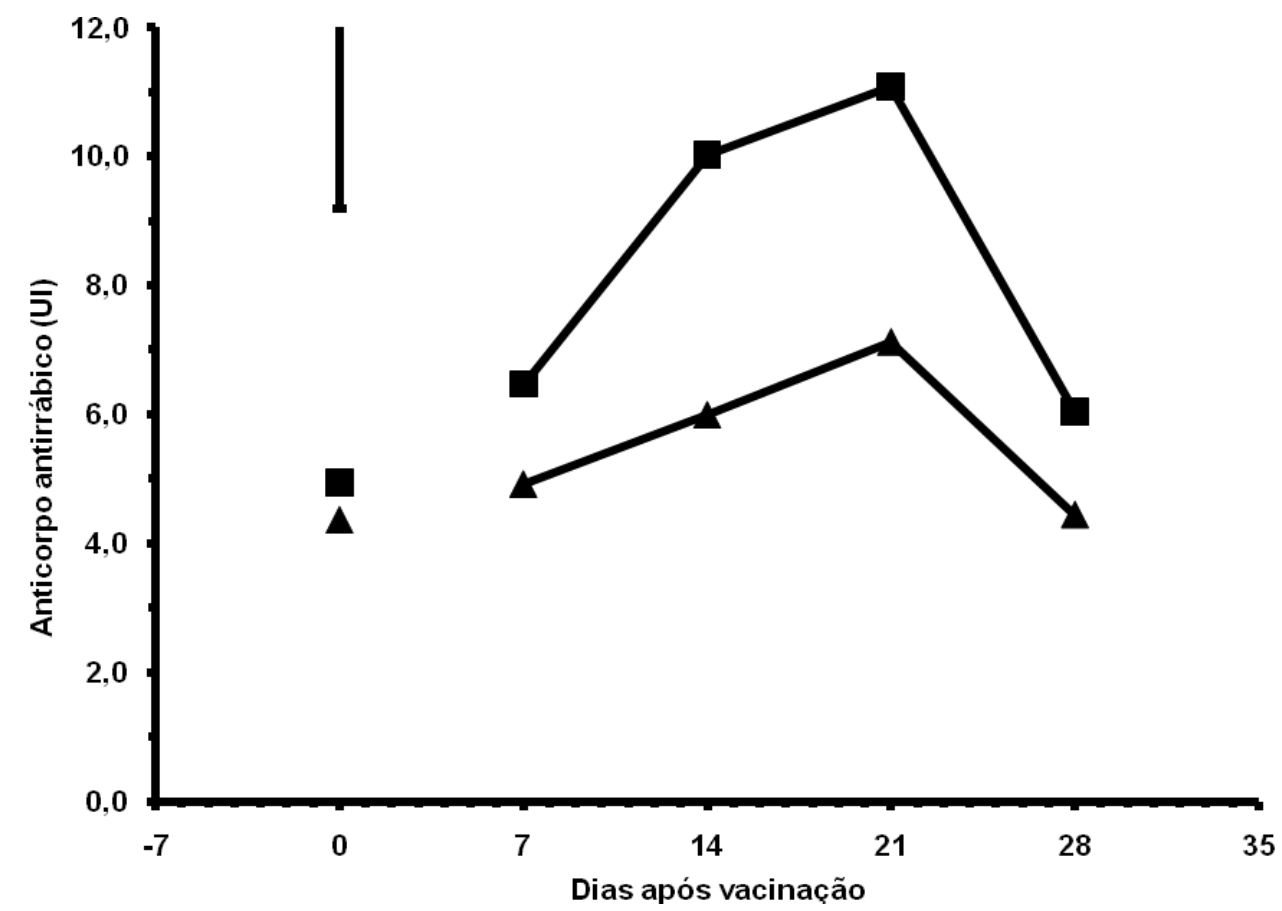

Figura 4. Título de anticorpos neutralizantes antivírus da raiva no soro em resposta à vacinação. Valores ajustados para o valor da mesma variável no dia 0. ( $\mathbf{\Delta}$ ) Homeopatia. (घ) Controle. 


\section{CONCLUSÕES}

Houve tendência de aumento na CCS do leite quando uma combinação homeopática foi fornecida para vacas com boa saúde da glândula mamária.

\section{REFERÊNCIAS BIBLIOGRÁFICAS}

BOERICK, O.E. Silicea terra. In: —. Boerick's repertory. 2009. Disponível em: <http://www.webhomeopath.com/uk/materia_me dica.php?remedyid=1070>. Acessado em: 27 fev. 2009.

CHABEL, J.C. Efeitos de um complexo homeopático em ovinos sob condições de restrição alimentar. 2007. 46f. Dissertação (Mestrado em Zootecnia) - Universidade Federal de Mato Grosso do Sul, Campo Grande, MS.

FAVORETTO, S.R.; CARRIERI, M.L.; TINO, M.S. et al. Simplified fluorescence inhibition microtest for the titration of rabies neutralizing antibodies. Rev. Inst. Med. Trop. São Paulo, v.35, p.171-175, 1993.

FIDELAK, C.; KLOCKE, P.; HEUWIESER, W. Homeopathic prophylaxis in dairy cows on an organic farm. Part 1 - Fertility. Dtsch. Tierarztl. Wochenschr., v.114, p.268-74., 2007.

HAHNEMANN, C.F.S. Organon of medicine. 1.ed. Leipzig, Alemanha, 1810. Disponível em: <http://www.homeopathyhome.com/reference/or ganon/organon.html>. Acessado em: 10 fev. 2009.

HAHNEMANN, C.F.S. Organon of medicine. 5.ed. Kothen, Alemanha, 1833. Disponível em: <http://www.homeopathyhome.com/reference/or ganon/organon.html>. Acessado em: $10 \mathrm{fev}$. 2009.

HAHNEMANN, C.F.S. Organon of medicine. 6.ed. Kothen, Alemanha, 1842. Disponível em: <http://www.homeopathyhome.com/reference/or ganon/organon.html>. Acessado em: $10 \mathrm{fev}$. 2009.

KLEIJNEN, J.; KNIPSCHILD, P.; RIET, G. Clinical trials of homoeopathy. Br. Med. J., v.302, p.316-323, 1991.
KLOCKE, P.; IVEMEYER, S.; HEIL, F. et al. Treatment of bovine sub-clinical mastitis with homeopathic remedies. In: QLIF CONGRESS, 3., 2007, Hohenheim, Germany. Proceedings..., 2007. Disponível em:

<http://orgprints.org/view/projects/int_conf_qlif2 007.html>. Acessado em: 18 out. 2007.

LINDE, K.; JONAS, W.B.; MELCHART, D. et al. Critical review and meta-analysis of serial agitated dilutions in experimental toxicology. Human Exp. Toxicol., v.13, p.481-492, 1994.

MANGIERI JUNIOR, R.; SOUTO, L.I.M.; MELVILLE, P.A. et al. Avaliação de tratamento homeopático na mastite bovina subclínica. Vet. Zootec., v.14, p.91-99, 2007.

MITIDIERO, A.M.A. Potencial do uso de homeopatia, bioterápicos e fitoterapia como opção na bovinocultura leiteira: avaliação dos aspectos sanitários e de produção. 2002. 119f. Dissertação (Mestrado em Agroecossistemas) Universidade Federal de Santa Catarina, Florianópolis, SC.

MONCAYO, F. Efficacy of homeopathic preparations of autogenous mastitis causing organisms in the prevention of mastitis in dairy cattle. Part II: effect of an autogenous nosode on the somatic cell count of lactating cows. Org. Farming Res. Found. Proj. Rep., v.99, p.4-7, 2000. Disponível em:

<http://ofrf.org/funded/reports/moncayo_99-

03.pdf>. Acessado em: 28 nov. 2008.

MORALES, R.V.; MENÉNDEZ, C.C.; PASOS, F.L. et al. Efecto de la aplicación del Reylac sobre la calidad de la leche en rebaños con mastitis subclinica bovina. Rev. Elect. Vet. REDVET, v.6, 2005. Disponível em: <http://www.veterinaria.org/revistas/redvet/n060 605.html>. Acessado em: 26 maio 2006.

REIS, L.S.L.S.; PARDO, P.E.; OBA, E. et al. Matricaria chamomilla $\mathrm{CH} 12$ decreases handling stress in Nelore calves. J. Vet. Sci., v.7, p.189192, 2006.

SILVA, J.R.M; BITENCOURT, L.L.; OLIVEIRA, B.M.L. et al. Suplementação de vacas leiteiras com homeopatia. I. Desempenho e digestibilidade. Arq. Bras. Med. Vet. Zootec., v.63, p.922-930, 2011. 
TEIXEIRA, M.A.; CARVALHO, T.B.S.; LUCENA, G.A.R. et al. Effect of biostimulatory homeopathic complex on mice subjected to feed stress. In: INTERNATIONAL CONGRESS ON THE FUTURE OF ANIMAL RESEARCH, 1., 2003, Rio de Janeiro, RJ. Anais... Rio de Janeiro: [s.n.], 2003. p.56.

VARSHNEY, J.P.; NARESH, R. Comparative efficacy of homeopathic and allopathic systems of medicine in the management of clinical mastitis of Indian dairy cows. Homeopathy, v.94, p.81-85, 2005.

VARSHNEY, J.P.; NARESH, R. Evaluation of a homeopathic complex in the clinical management of udder diseases of riverine buffaloes. Homeopathy, v.93, p.17-20, 2004.
WERNER, C.; SUNDRUM, A. Comparison of homeopathic and chemotherapeutic treatment strategies in the case of bovine clinical mastitis. In: JOINT ORGANIC CONGRESS, 8., 2006. Odense, Denmark. Proceedings... 2006. Disponível em:

<http://orgprints.org/secure/00007403/01/Odense Hom.doc>. Acessado em: 15 jan. 2008.

YASGUR, J. Complex or combination? (letters to the editor). Homeopathy, v.94, p.264-266, 2005. 